\title{
Low-Velocity Zone Under Long Valley as Determined From Teleseismic Events
}

\author{
Don W. Steeples ${ }^{1}$ and H. M. IYer
}

U.S. Geological Survey, Menlo Park, California 94025

\begin{abstract}
A temporary seismograph station network was used to estimate teleseismic $P$ wave residuals in the vicinity of Long Valley geothermal area, California. Relative $P$ wave delays of $0.3 \mathrm{~s}$ persist at stations in the west central part of the Long Valley caldera after regional and near-surface effects have been removed. Ray tracing indicates that low-velocity material exists beneath the caldera at depths greater than $7 \mathrm{~km}$ and less than $\mathbf{4 0} \mathrm{km}$, probably less than $25 \mathrm{~km}$. The velocity contrast with normal crust must be at least $5 \%$ to satisfy the data and is probably in the range $10-15 \%$. We believe that the low velocity indicates anomalously hot rock at depth and that relative teleseismic $P$ residuals may be useful for investigation of sources of geothermal energy.
\end{abstract}

\section{INTRODUCTION}

This paper reports on the results of a study using teleseismic $P$ wave arrival time residuals at temporary seismograph networks centered on the Long Valley caldera, California. The method allowed the exploration of the crustal velocity structure to a depth of about $40 \mathrm{~km}$ in the caldera. The recording of distant earthquakes is a commonly used method of extracting velocity information about the crust and upper mantle. For example, such studies have been made using the large aperture seismic array (Lasa) in Montana [Iyer and Healy, 1972; Chinnery and Toksoz, 1967], the Tonto Forest Seismic Observatory in Arizona [Niazi and Anderson, 1965], and the U.S. Geological Survey (USGS) seismic network in Yellowstone [Iyer et al., 1974; Iyer, 1975]. The investigation at Yellowstone is the first such study in a known geothermal area, and indeed the Yellowstone network was installed for the purpose of investigating passive seismic techniques in such areas. Relative teleseismic $P$ delays at Yellowstone were interpreted in terms of an anomalous hot zone extending downward to at least 250$\mathrm{km}$ depth (possibly to $400 \mathrm{~km}$ ), well into the upper mantle.

Press and Biehler [1964] used correlations between $P$ wave delays and gravity anomalies to infer higher than normal temperatures in the lower crust beneath the Sierra Nevada batholith. An alternate interpretation of their data may be possible in view of later work involving azimuthal variation in teleseismic $P$ residuals. Bolt and Nuttli [1966] and Nuttli and Bolt [1969] investigated relative teleseismic $P$ residuals in northern California. They found azimuthal variations of up to $2.4 \mathrm{~s}$ between Shasta and Berkeley for relative residuals, smaller effects being observed at other stations. They suggested that the azimuthal effects were due to changes in depth and/or thickness of the low-velocity layer in the upper mantle. Koizumi et al. [1973] interpreted early teleseismic arrivals at some stations in Nevada as being due to a dipping lithospheric plate in the upper mantle (i.e., a fossil subduction zone). Regional effects such as these are not present at Long Valley (as will be discussed later).

The following information is needed to calculate relative teleseismic $P$ residuals: (1) hypocenter location and origin time $T_{0}$ of the earthquake and (2) location and arrival time $T A_{l}$ at

${ }^{1}$ Now at Kansas Geological Survey, University of Kansas, Lawrence, Kansas 66044.

Copyright (c) 1976 by the American Geophysical Union. the $i$ th station. Expected travel times $T E_{i}$ from each hypocenter to each station are read (by computer in the present work) from the Herrin [1968] tables. The absolute $P$ residual $R A_{i}$ for the $i$ th station is calculated by subtraction:

$$
R A_{t}=\left(T A_{t}-T_{0}\right)-T E_{t}
$$

Absolute residuals are of little use in local crustal studies because they are a measure of inaccuracies in the computed hypocenter, source-station effects, and how much the true earth $P$ wave velocity differs from the Herrin [1968] earth $P$ wave velocity model along path lengths of thousands of kilometers in the mantle. Hence for local crustal studies, relative $P$ residuals $R R_{\imath}$ are calculated by subtracting the absolute $P$ residual at some reference station $R A R$ from the absolute $P$ residuals at the $i$ th station:

$$
R R_{\imath}=R A_{\imath}-R A R
$$

If $R R_{i}$ is positive, a delay must have occurred somewhere along the ray path from the earthquake hypocenter to the $i$ th station relative to the ray path to the reference station. Since a teleseismic focus represents essentially a point source at its origin, the rays to different stations of a small array follow very similar ray paths until they are far from the focus. Since the lower mantle is thought to be homogeneous on the scale of a few kilometers, it is reasonable to assume that most of the contribution to relative residuals of a local network comes from crustal or upper mantle velocity differences beneath the stations. The ramifications of this assumption are discussed in detail later.

The reference station should be situated such that ray paths to the station represent some average or 'normal' path that does not penetrate the volume of rock under investigation. This requires the reference station to be outside the suspected anomalous area under investigation but at the same time close to the area to keep any regional effects to a minimum. The technique is identical to that used by others [Utsu, 1973; Wyss and Holcomb, 1973; Cramer and Kovach, 1974] searching for temporal variation in $P$ residuals caused by physical changes in the vicinity of impending earthquake hypocenters. The only difference is that the present emphasis is on spatial rather than temporal variations.

Signals from distant earthquakes are particularly useful as a supplement to refraction or reflection surveys for local crustal studies because the ray paths are nearly vertical when they reach the surface. Estimated angles of incidence [Richter, 
TABLE 1. Station Locations

\begin{tabular}{|c|c|c|c|c|}
\hline \multirow[b]{2}{*}{ Station } & \multicolumn{2}{|c|}{ North Latitude } & \multicolumn{2}{|c|}{ West Longitude } \\
\hline & deg & $\min$ & deg & $\min$ \\
\hline ML01 & 37 & 45.63 & 119 & 06.52 \\
\hline ML04 & 37 & 57.49 & 119 & 09.03 \\
\hline ML05 & 37 & 49.86 & 118 & 25.98 \\
\hline ML06 & 37 & 45.13 & 118 & 46.03 \\
\hline ML07 & 37 & 38.06 & 118 & 39.33 \\
\hline ML08 & 37 & 36.22 & 118 & 59.60 \\
\hline ML09 & 37 & 35.85 & 118 & 20.23 \\
\hline ML10 & 37 & 34.98 & 118 & 33.15 \\
\hline ML11 & 37 & 32.92 & 118 & 48.82 \\
\hline ML12 & 37 & 29.22 & 118 & 38.19 \\
\hline ML13 & 37 & 28.60 & 118 & 28.65 \\
\hline ML14 & 37 & 22.69 & 118 & 33.60 \\
\hline ML16 & 37 & 23.04 & 118 & 40.49 \\
\hline ML17 & 37 & 21.00 & 118 & 16.97 \\
\hline ML18 & 37 & 13.57 & 118 & 36.24 \\
\hline LVA & 37 & 36.16 & 118 & 59.68 \\
\hline LVB & 27 & 36.13 & 118 & 51.15 \\
\hline LVC & 37 & 34.97 & 118 & 33.17 \\
\hline LVD & 37 & 45.14 & 118 & 46.03 \\
\hline LVE & 37 & 46.82 & 119 & 04.96 \\
\hline LVF & 37 & 39.03 & 119 & 03.01 \\
\hline LVG & 37 & 44.41 & 118 & 57.81 \\
\hline LVI & 37 & 44.20 & 118 & 50.36 \\
\hline LVJ & 37 & 38.50 & 118 & 48.37 \\
\hline LVK & 37 & 42.73 & 118 & 41.28 \\
\hline LVL & 37 & 38.05 & 118 & 39.38 \\
\hline LVM & 37 & 35.22 & 118 & 40.42 \\
\hline LVN & 37 & 35.87 & 118 & 20.25 \\
\hline LVO & 37 & 29.21 & 118 & 38.19 \\
\hline LVP & 37 & 23.03 & 118 & 33.14 \\
\hline LVR & 37 & 38.82 & 118 & 55.67 \\
\hline LVS & 37 & 35.47 & 118 & 50.07 \\
\hline LVP1 & 37 & 39.53 & 118 & 46.29 \\
\hline LVP2 & 37 & 40.25 & 118 & 51.25 \\
\hline LVP3 & 37 & 41.75 & 118 & 53.36 \\
\hline LVP4 & 37 & 42.29 & 118 & 58.14 \\
\hline LVCF & 37 & 37.43 & 118 & 46.73 \\
\hline LVMA & 37 & 43.39 & 118 & 50.25 \\
\hline LV01 & 37 & 38.12 & 118 & 48.32 \\
\hline LV02 & 37 & 38.64 & 118 & 47.80 \\
\hline LV03 & 37 & 39.27 & 118 & 47.25 \\
\hline LV04 & 37 & 40.15 & 118 & 46.75 \\
\hline LV05 & 37 & 40.93 & 118 & 46.28 \\
\hline LV06 & 37 & 41.50 & 118 & 45.89 \\
\hline LV07 & 37 & 38.38 & 118 & 46.90 \\
\hline LV08 & 37 & 38.27 & 118 & 45.05 \\
\hline LVII & 37 & 40.01 & 118 & 48.78 \\
\hline LVI2 & 37 & 40.46 & 118 & 48.25 \\
\hline LV16 & 37 & 39.12 & 118 & 50.14 \\
\hline LV 17 & 37 & 39.63 & 118 & 49.18 \\
\hline LV18 & 37 & 40.02 & 118 & 54.31 \\
\hline LV19 & 37 & 40.40 & 118 & 53.17 \\
\hline LV20 & 37 & 40.61 & 118 & 52.20 \\
\hline LV21 & 37 & 40.30 & 118 & 51.57 \\
\hline LV22 & 37 & 41.05 & 118 & 50.39 \\
\hline LV23 & 37 & 40.75 & 118 & 49.88 \\
\hline LV24 & 37 & 40.62 & 118 & 49.12 \\
\hline LV25 & 37 & 40.97 & 118 & 48.67 \\
\hline LV34 & 37 & 44.46 & 118 & 51.26 \\
\hline LV35 & 37 & 44.62 & 118 & 52.09 \\
\hline LV36 & 37 & 44.66 & 118 & 52.97 \\
\hline LV37 & 37 & 44.72 & 118 & 53.75 \\
\hline LV38 & 37 & 44.87 & 118 & 54.46 \\
\hline LV39 & 37 & 45.01 & 118 & 55.87 \\
\hline LV40 & 37 & 44.88 & 118 & 56.65 \\
\hline LV4I & 37 & 43.25 & 118 & 59.82 \\
\hline LV42 & 37 & 42.83 & 118 & 55.66 \\
\hline LV43 & 37 & 40.82 & 118 & 59.67 \\
\hline LV44 & 37 & 40.83 & 118 & 57.02 \\
\hline LV46 & 37 & 42.38 & 118 & 51.80 \\
\hline LV47 & 37 & 41.36 & 118 & 54.73 \\
\hline LV48 & 37 & 43.48 & 118 & 52.66 \\
\hline
\end{tabular}

TABLE I. (continued)

\begin{tabular}{lccccc}
\hline & \multicolumn{2}{c}{ North Latitude } & & \multicolumn{2}{c}{ West Longitude } \\
\cline { 2 - 3 } \cline { 6 - 6 } Station & $\operatorname{deg}$ & $\min$ & & $\operatorname{deg}$ & $\min$ \\
\hline LV49 & 37 & 42.00 & & 118 & 45.67 \\
LV57 & 37 & 42.38 & & 118 & 46.01 \\
LV58 & 37 & 43.00 & & 118 & 46.41 \\
LV59 & 37 & 43.65 & & 118 & 47.04 \\
LV60 & 37 & 44.20 & & 118 & 46.23 \\
LV63 & 37 & 44.63 & & 118 & 48.41 \\
\hline
\end{tabular}

Seventy-eight different station locations were used. ML stations operated for 20 days in 1970 (except 1, 4, and 10, which only operated for about 10 days). LV stations with three-letter names operated during the whole month of May 1973, except B, O, P, and S, which were moved the last week of May. LV stations A, C, D, and E operated through the month of June also. LV stations with fourcharacter designations operated for a few hours to a few days each. A complete schedule of operation is given by Iyer and Hitchcock [1976].

1958] for typical teleseisms used in this study ranged from about $28^{\circ}$ from vertical for events in Alaska ( $\Delta$ (great circle distance) approximately $40^{\circ}$ ) to about $19^{\circ}$ from vertical for events from Japan ( $\Delta$ approximately $75^{\circ}$ ). Local refraction surveys provide velocity information only for the upper few kilometers of the crust. The information supplied by local refraction or reflection surveys is essential to the interpretation of teleseismic $\boldsymbol{P}$ residuals because it enables us to remove nearsurface effects and concentrate on deeper effects.

\section{Data}

It should be pointed out that the data used in the preparation of this paper were gathered from seismic arrays designed to perform entirely different functions than a study of teleseismic $\boldsymbol{P}$ delays. For that reason this study should by no means be construed to place limits on the accuracy or precision with which the low-velocity anomaly described herein may eventually be delineated. It should also be pointed out that the western United States is in an ideal position geographically to use the $P$ delay method, since many teleseisms arrive along northwest-southeast azimuths approximately $180^{\circ}$ apart as shown in Table 2 . From theoretical wave propagation limits the $\boldsymbol{P}$ delay method is incapable of detecting a 'root' or pipe extending down into the upper mantle if such a pipe is less than perhaps a few kilometers in diameter.

Sixteen portable seismograph stations were deployed for approximately 9 weeks in the Long Valley vicinity to record microearthquakes [Steeples and Pitt, 1976, this issue] and monitor seismic noise [Iyer and Hitchcock, 1976, this issue]. All well-recorded teleseisms that occurred during these two studies were analyzed. The station locations and teleseismic events used are given in Tables 1 and 2, respectively.

The portable seismograph system is described in detail by Eaton et al. [1970]. Since the system was designed primarily to record microearthquakes, picking first arrivals of small teleseisms recorded by the equipment is difficult and uncertain at best. Large teleseisms occur infrequently, and the data set is limited by short periods of recording, so the problem becomes serious when small teleseisms must be used to increase the size of the data set.

Some of the uncertainties of emergent first arrivals can be eliminated by timing the first peak or first trough. When this 
TABLE 2. Teleseisms Used

\begin{tabular}{|c|c|c|c|c|c|c|c|c|c|c|}
\hline \multirow[b]{2}{*}{ No. } & \multirow[b]{2}{*}{ Locality } & \multirow[b]{2}{*}{ Date } & \multirow[b]{2}{*}{ Origin } & \multicolumn{2}{|c|}{ Latitude* } & \multicolumn{2}{|c|}{ Longitude* } & \multirow{2}{*}{$\begin{array}{c}\text { Depth, } \\
\text { km }\end{array}$} & \multirow{2}{*}{$\begin{array}{l}\text { Epicenter } \\
\text { Azimuth } \\
\text { From } \\
\text { LVC, deg }\end{array}$} & \multirow{2}{*}{$\begin{array}{c}\text { Epicenter } \\
\text { Distance } \\
\text { From } \\
\text { LVC, deg }\end{array}$} \\
\hline & & & & deg & $\min$ & $\operatorname{deg}$ & $\min$ & & & \\
\hline \multicolumn{11}{|c|}{1970 Data } \\
\hline 1 & Kamchatka & Oct. 8 & $04: 53: 21.8$ & +53 & 48.0 & -160 & 24.0 & 59 & 315 & 56 \\
\hline 2 & Andreanof & Oct. 8 & $13: 02: 05.0$ & +50 & 24.0 & +176 & 12.0 & 38 & 307 & 42 \\
\hline 3 & Russia-China & Oct. 12 & $09: 33: 37.0$ & +42 & 48.0 & -131 & 00.0 & 555 & 315 & 78 \\
\hline 4 & Novaya Zemlya & Oct. 14 & $05: 59: 57.1$ & +73 & 18.0 & -55 & 06.0 & 1 & 2 & 69 \\
\hline 5 & Fiji & Oct. 14 & $10: 40: 58.0$ & -18 & 06.0 & +178 & 30.0 & 609 & 237 & 79 \\
\hline 6 & Honshu & Oct. 16 & $05: 26: 13.0$ & +39 & 18.0 & -140 & 42.0 & 24 & 308 & 74 \\
\hline \multicolumn{11}{|c|}{1973 Data } \\
\hline 7 & Fij1 & April 30 & $08: 39: 07.7$ & -17 & 30.0 & -179 & 36.0 & 613 & 239 & 80 \\
\hline 8 & Fiji & May 3 & $13: 26: 31.0$ & -17 & 54.0 & +178 & 24.0 & 600 & 237 & 79 \\
\hline 9 & Russia & May 6 & $14: 39: 28.1$ & +43 & 30.0 & -132 & 18.0 & 497 & 315 & 77 \\
\hline 10 & Fiji & May 8 & $04: 44: 56.4$ & -17 & 36.0 & +178 & 54.0 & 543 & 238 & 79 \\
\hline 11 & Chile & May 10 & $07: 55: 07.6$ & -25 & 36.0 & +70 & 24.0 & 44 & 136 & 77 \\
\hline 12 & Fiji & May 14 & $17: 11: 13.8$ & -16 & 36.0 & -175 & 54.0 & 54 & 242 & 82 \\
\hline 13 & Fiji & May 14 & $21: 15: 47.9$ & -22 & 00.0 & +179 & 06.0 & 501 & 235 & 82 \\
\hline 14 & Honshu & May 17 & $15: 44: 19.5$ & +33 & 06.0 & -140 & 42.0 & 62 & 303 & 78 \\
\hline 15 & Fiji & May 27 & $06: 38: 13.4$ & -21 & 18.0 & +177 & 54.0 & 422 & 234 & 81 \\
\hline 16 & Rat Island & May 29 & $01: 46: 44.9$ & +51 & 42.0 & -176 & 12.0 & 46 & 309 & 47 \\
\hline 17 & Peru & May 30 & $12: 39: 54.3$ & -14 & 06.0 & +72 & 48.0 & 90 & 131 & 67 \\
\hline 18 & Gulf of California & May 30 & $17: 33: 51.0$ & +26 & 18.0 & +110 & 42.0 & 33 & 147 & 13 \\
\hline 19 & Guatemala & May 31 & $05: 39: 18.8$ & +13 & 54.0 & +90 & 54.0 & 99 & 126 & 34 \\
\hline 20 & Unimac & May 29 & $06: 14: 22.3$ & +54 & 00.0 & +163 & 48.0 & 30 & 312 & 35 \\
\hline 21 & Ecuador & May 30 & $04: 38: 01.8$ & -02 & 18.0 & +78 & 30.0 & 111 & 128 & 54 \\
\hline 22 & Guatemala & June 7 & $18: 32: 42.9$ & +14 & 18.0 & +92 & 00.0 & 78 & 127 & 33 \\
\hline 23 & Guatemala & June 7 & $18: 34: 46.3$ & +14 & 12.0 & +91 & 54.0 & 70 & 127 & 33 \\
\hline 24 & Solomon & June 9 & $08: 21: 27.3$ & -10 & 18.0 & -161 & 24.0 & 70 & 255 & 88 \\
\hline 25 & Andreanof & June 15 & $13: 38: 23.1$ & +51 & 18.0 & +179 & 24.0 & 50 & 308 & 44 \\
\hline 26 & Fiji & June 15 & $23: 04: 58.6$ & -25 & 54.0 & +177 & 24.0 & 94 & 231 & 84 \\
\hline 27 & Hokkaido & June 17 & $03: 55: 02.9$ & +43 & 12.0 & -145 & 48.0 & 48 & 309 & 69 \\
\hline 28 & Hokkaido & June 17 & $20: 37: 57.3$ & +42 & 42.0 & -146 & 00.0 & 50 & 308 & 69 \\
\hline 29 & So uthern Alaska & June 18 & $10: 17: 26.3$ & +52 & 12.0 & +164 & 54.0 & 15 & 310 & 35 \\
\hline 30 & Hokkaido & June 18 & $17: 45: 43.7$ & +42 & 30.0 & -146 & 00.0 & 29 & 308 & 69 \\
\hline 31 & Bolivia & June 19 & $04: 46: 01.5$ & -20 & 48.0 & +68 & 48.0 & 118 & 132 & 75 \\
\hline 32 & Kermadec & June 20 & $12: 01: 56.7$ & -28 & 30.0 & +176 & 48.0 & 41 & 229 & 85 \\
\hline 33 & Andreanof & June 23 & $05: 26: 49.0$ & +51 & 54.0 & +176 & 54.0 & 62 & 309 & 43 \\
\hline 34 & Kuril & June 24 & $02: 43: 25.5$ & +43 & 18.0 & -146 & 24.0 & 50 & 309 & 69 \\
\hline 35 & Kuril & June 24 & 03:04: 18.6 & +43 & 12.0 & -146 & 48.0 & 55 & 308 & 68 \\
\hline 36 & Kuril & June 24 & $03: 28: 38.5$ & +43 & 18.0 & -146 & 48.0 & 47 & 309 & 68 \\
\hline 37 & Kuril & June 24 & $05: 07: 46.8$ & +43 & 06.0 & -146 & 36.0 & 44 & 308 & 69 \\
\hline 38 & South Pacific & June 25 & $15: 03: 18.7$ & -35 & 54.0 & +103 & 54.0 & 33 & 168 & 74 \\
\hline 39 & Sitka & July 1 & $13: 33: 34.6$ & +57 & 48.0 & +137 & 18.0 & 33 & 335 & 24 \\
\hline
\end{tabular}

*Positive denotes north and west; negative denotes south and east.

method was first used to time the teleseisms, the results showed considerable scatter but suggested that the data might contain significant new information about deep crustal velocity beneath Long Valley caldera.

Instead of using the peak and trough method, we tried timing the zero crossing (i.e., the end of the first cycle) (Figure 1). Somewhat to our surprise the scatter in the relative residuals decreased significantly when this technique was used. The standard deviations of relative residuals for a given azimuth decreased by approximately a factor of 2 at most of the stations.

Other investigators at the U.S. Geological Survey have subsequently adopted the zero crossings as timing points (C. Cramer and J. Evans, oral communication, 1975). They have statistically compared the technique to the peak-trough method and the first-break method. Both agree that the zerocrossing method is much superior to first breaks and is slightly better than the peak-trough method, particularly since the zero crossings are more objective picks.

There are several important advantages to the zero-crossing technique:
1. The second zero crossing often crosses the zeroamplitude line at a very steep angle, thus effectively filtering high-frequency noise and reducing the picking uncertainty. It is usually possible to attain a reading accuracy of $\pm 0.02 \mathrm{~s}$.

2. The uncertainty due to changes in wave shape is small because of the very small aperture $\left(\Delta=1 / 2^{\circ}\right)$ of the seismic array used in this experiment. For the best events both the first arrivals and second zero crossings were timed, and the standard deviations of the period of the first cycle for a particular event were generally in the range $0.04-0.06 \mathrm{~s}$. This provides assurance that the travel time anomalies observed in the caldera are not caused by changes in wave shape or the picking technique. Most events recorded had first-cycle periods of very nearly $1 \mathrm{~s}$, and the wave shape of the first pulse was stable across the array. Mack [1969] noted changes in signal shape across the Lasa in Montana, but a look at his published data shows that the first cycle was relatively uniform across the array.

3. For weakly recorded teleseisms resulting from small event magnitudes or low station sensitivity, the first peak or trough, the first zero crossing, and the first break are often ob- 


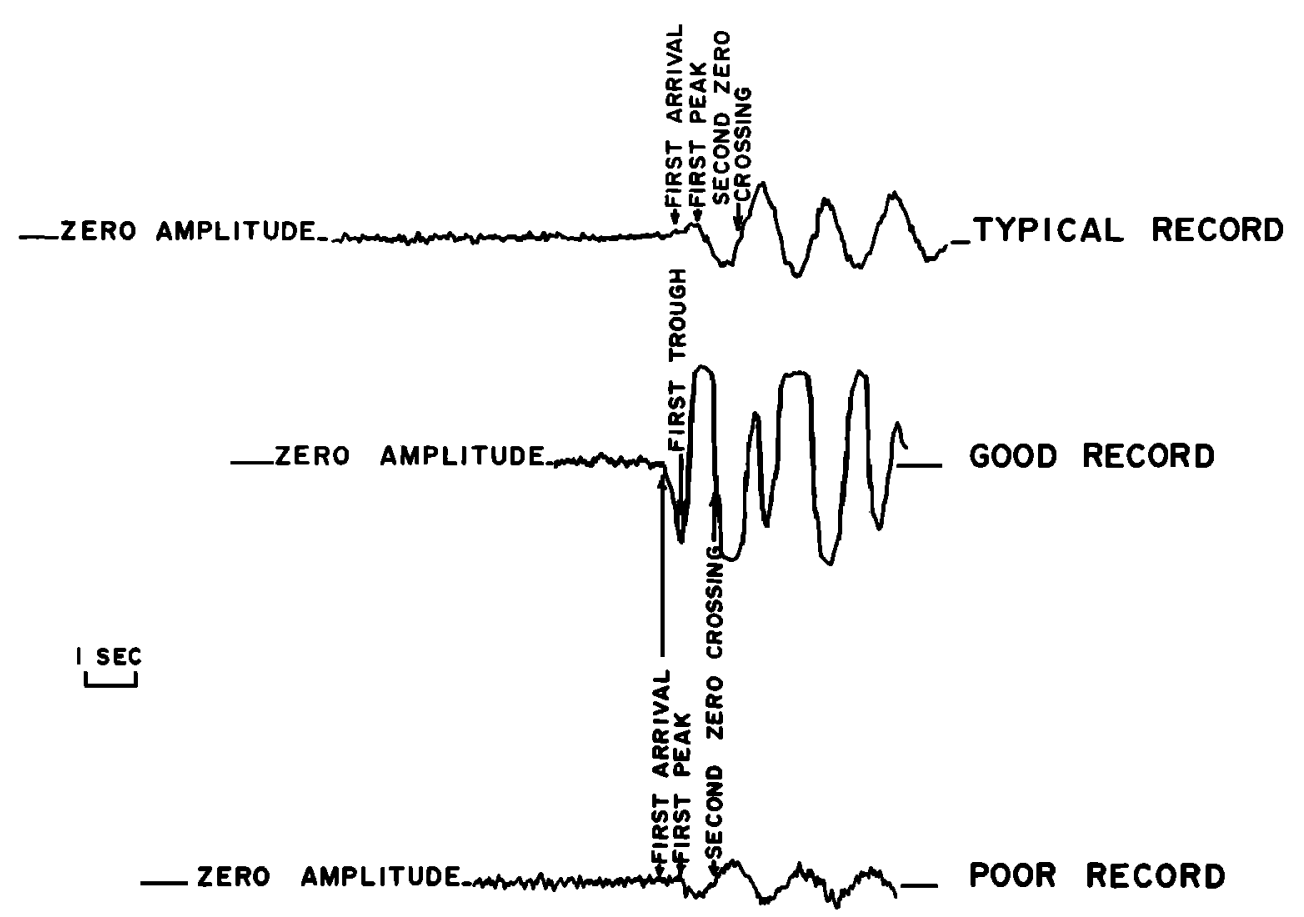

Fig. 1. Tracings of seismograms illustrating various picking points.

scured by noise or attenuated in such a way that the second zero crossing is the first and only reliable pick (Figure 1). Readings beyond the second zero crossing introduce intolerable levels of uncertainty into the data as a result of reflections, scattering, diffraction, and other common wave deformation phenomena [see Mack, 1969]. Since the present investigation deals with relative residuals, it is most important to pick the same phase of the signal at all stations.

The data set was recorded in an analog fashion on magnetic tape and played back with an ink-squirting strip chart recorder at a paper speed of $1 \mathrm{~cm} / \mathrm{s}$. Two radio station WWVB timing traces were played back parallel to the signal trace. Zero crossings are read to $0.01 \mathrm{~s}$, and picking errors vary from $0.02 \mathrm{~s}$ for the best seismograms to about $\pm 0.05 \mathrm{~s}$ for signals that do not cross zero at a very steep angle. The uncertainty due to previously mentioned changes in wave shape is of the order of $0.04-0.06 \mathrm{~s}$. Hence the maximum likely uncertainty for a given reading is normally about $\pm 0.11 \mathrm{~s}$ for the lower-quality teleseisms used. These error estimates are somewhat subjective but reasonable, and they are based on experience and discussions with other USGS investigators.

The criterion for playback of a teleseism was that it be well recorded at Casa Diablo Mountain (LVC), the reference station (Figure 2). The uncertainty of the timing at LVC is $\pm 0.02 \mathrm{~s}$ for picking error and $\pm 0.06 \mathrm{~s}$ for wave shape change, since all events except one at the reference station had excellent second zero crossings. Since we are dealing with relative residuals, the usual maximum uncertainty in a relative residual value is the sum of the uncertainties at the reference station and the station of interest, in this case about $0.19 \mathrm{~s}$ for the poor events and about $0.16 \mathrm{~s}$ for the good events.

At many stations three or more readings from the same azimuth are available. Residuals at these stations were averaged for each approach azimuth, and standard deviations of the data were generally in the range 0.04-0.11 s. We conclude that the likely uncertainty of average relative residual of three or more events from a particular azimuth at a given station is about $0.1 \mathrm{~s}$.

The interpretation of $P$ delay data in some cases requires removal of regional azimuthal variations [see Press and Biehler, 1964; Bolt and Nuttli, 1966]. As is shown below, such a correction was not needed at Long Valley, partly because of the local nature of the array.

Figure 2 shows relative residuals with respect to LVC for stations outside the Long Valley caldera. Some of these readings (six events) come from a network that operated for 20 days in 1970 to record microearthquakes in the northern Owens Valley-Mono Lake region [Pitt and Steeples, 1975]. The data in Figure 2 indicate that regional effects for events from the northwest and southeast azimuths are less than $0.05 \mathrm{~s}$, even though two stations have values of +0.16 and -0.18 for events from the southeast. The limited data from southwest events suggest a possibility of relative arrivals southwest and northwest of the Long Valley caldera $0.2 \mathrm{~s}$ earlier than those at stations near Bishop, which is about $50 \mathrm{~km}$ southeast of Long Valley. Elevation corrections were not used but would add 0.01-0.03 s to residuals in the caldera, since the elevation of the reference station (LVC) is $50-200 \mathrm{~m}$ greater than the elevation at stations in the caldera.

Figure $3 a$ shows stations in and near the Long Valley caldera that recorded at least one event from the northwest. Relative delays (positive residuals) are about $0.2 \mathrm{~s}$ near the northwest corner of the caldera, increasing to about $0.5 \mathrm{~s}$ toward the center of the caldera.

Figure $3 b$ shows stations that recorded at least one event from the southeast. For this azimuth, delays of the order of $0.5 \mathrm{~s}$ are present in the northwest section of the caldera. Thus the largest delays are for stations on the opposite side of the caldera from the approach direction. As is shown below, this change in the spatial pattern for delays for opposite azimuths can be caused only by material deep under the center of the caldera. 
Interpretation of the delays requires the removal of nearsurface effects. Three different techniques were used to estimate the surface effects:

1. A crustal refraction survey by Hill [1976, this issue] was centered on the caldera. Ray tracing and travel time calculations show that the effect of the upper $6 \mathrm{~km}$ of the crust should produce only delays of the order of $0.15-0.2 \mathrm{~s}$ in most of the caldera including the area where 0.5 -s delays were found. The travel times are highly dependent on the thickness of shallow sediment near the surface (velocity $1.5-1.7 \mathrm{~km} / \mathrm{s}$ ) along the Owens River in the northeast section of the caldera. Delays approaching $0.4 \mathrm{~s}$ may occur in this region, but it is east of the deep anomalous zone.

2. Teleseismic rays that are recorded near the edge of the caldera but that do not pass up through the center of the caldera show relative delays of $0.2 \mathrm{~s}$, whereas some of the same stations show 0.5 -s delays for ray paths that traverse the center of the caldera (Figure $4 c$ ). This indicates that the near-surface effects are of the order of $0.2 \mathrm{~s}$ and that deep effects are $0.3 \mathrm{~s}$ beneath the center of the caldera.

3. Some of the larger local microearthquakes south and east of the Long Valley caldera [Steeples and Pitt. 1976] could be well located without the use of arrival times from stations within the caldera (LVG, LVI, LVJ). The local earthquake residuals thus obtained at these three caldera stations are a measure of near-surface velocity anomalies in the caldera. Stations LVG and LVJ had local residuals suggesting nearsurface delays of $0.2 \mathrm{~s}$. Station LVI, which is near Owens
River, has local residuals indicating near-surface delays of $0.30-0.35 \mathrm{~s}$.

Figures $4 a$ and $4 b$ show residuals from northwest and southeast at stations in the caldera and vicinity after estimated surface effects have been removed. Surface effects were taken at $0.35 \mathrm{~s}$ near Owens River Valley (in the hachured area of Figure $4 c$ ) and $0.2 \mathrm{~s}$ elsewhere. Only stations in the caldera that had readings from both northwest and southeast are shown in Figure $4 c$. The estimated near-surface effects have been removed at the five stations shown. Note the azimuthally dependent differences of $t$ to $f s$ as mentioned in the second technique above. Figures $4 a$ and $4 b$ show all the available data from the two different azimuths.

An attempt was also made to use regional events from the San Andreas Fault and explosions from the Nevada Test Site in the hope of further constraining the low-velocity volume in the caldera. That effort was a failure because the Long Valley caldera was at or near the critical distance from both sources and it was impossible to distinguish $P n, P^{*}$, and $P g$.

\section{Discussion}

Figures $5 a$ and $5 b$ show two sectional views of the caldera using readings in a zone $2 \mathrm{~km}$ wide centered along $\mathrm{AA}^{\prime}$ of Figure $4 c$ with typical distant ray paths drawn from northwest and southeast teleseisms to the surface. Unfortunately, few large events were recorded from the southeast azimuth because of the relatively short period of recording. Thus there is a scarcity of ray paths from the southeast in a critical part of our

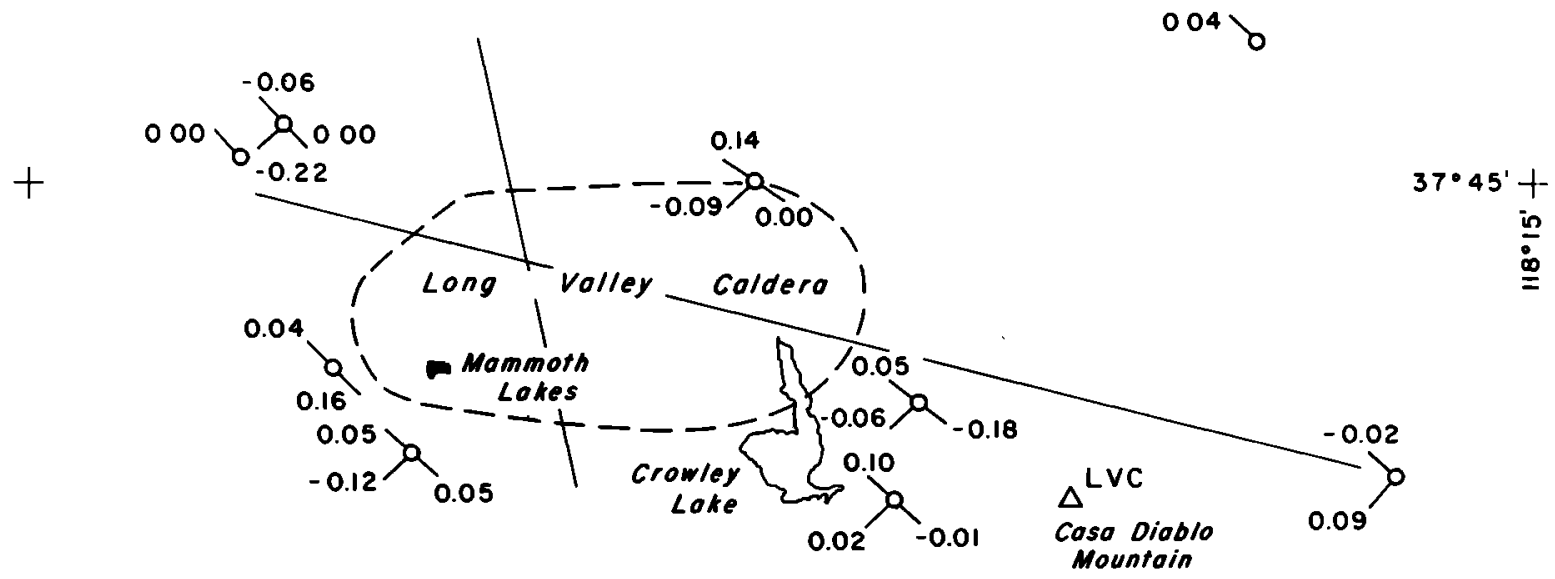

EXPLANATION

$\Delta$ Reference stotion

- Seismograph station

- Refroction survey line

AnEA or uAP

o

10 $20 \mathrm{~km}$<smiles>O=S(=O)(O)O[Na]</smiles><smiles>Oc1ccc(O)c(O)c1</smiles>

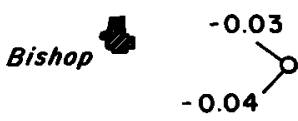

Fig. 2. Teleseismic $\boldsymbol{P}$ wave residuals relative to Casa Diablo Mountain (LVC) at stations surrounding the Long Valley caldera. The lines from the stations show the three primary azimuths used. Each number is an average of three or more residuals from the azimuths indicated by the lines. Refraction survey lines are from Hill [1976]. 


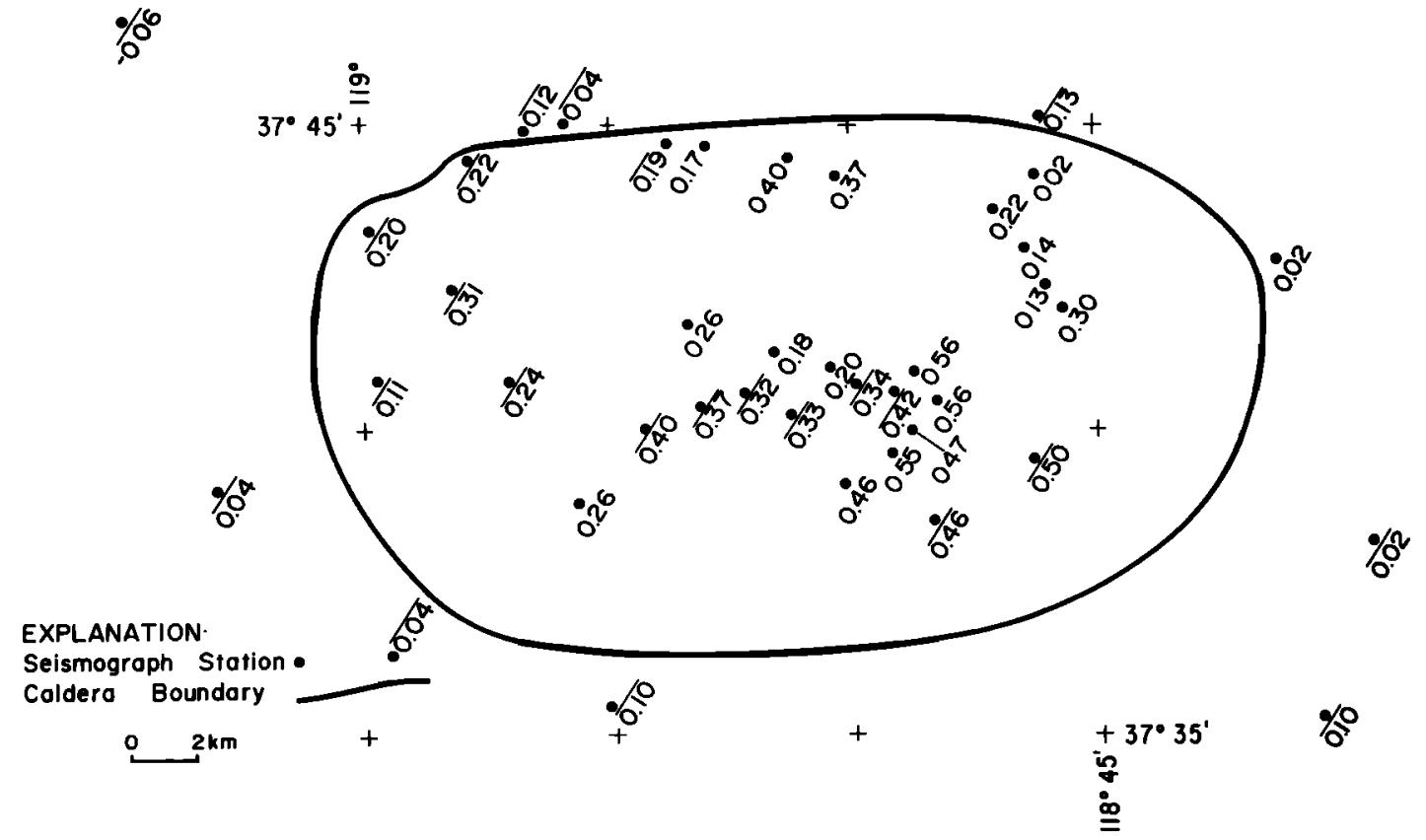

Fig. 3a. Teleseismic $P$ wave residuals for events from the northwest relative to LVC (not shown). Residual values with bars are averages of three or more events and values without bars are averages of only one or two events. Uncertainty expected is $\pm 0.1 \mathrm{~s}$ for barred values and $\pm 0.16 \mathrm{~s}$ for unbarred values.

model. It is assumed that somewhere along these ray paths in the crust below 7-km depth (the vertical extent of the refraction survey [Hill, 1976, this issue]) a velocity anomaly exists. We consider velocity anomaly models with decreases of 5,10 , and $15 \%$ in the $P$ wave velocity, and the path lengths required to produce the observed delays. The equation governing path length required is

$$
L_{P}=(\Delta t)\left(V_{1}\right)\left(V_{2}\right) /\left(V_{1}-V_{2}\right)
$$

where $L_{P}$ is path length, $\Delta t$ is amount of time delay, $V_{1}$ is normal crustal velocity (taken as $6.0 \mathrm{~km} / \mathrm{s}$ ), and $V_{2}$ is the anomalous low velocity.

When this equation is used, a $5 \%$ velocity decrease requires $34.2 \mathrm{~km}$ of anomalous ray path to produce $0.3-\mathrm{s}$ delay. Ray

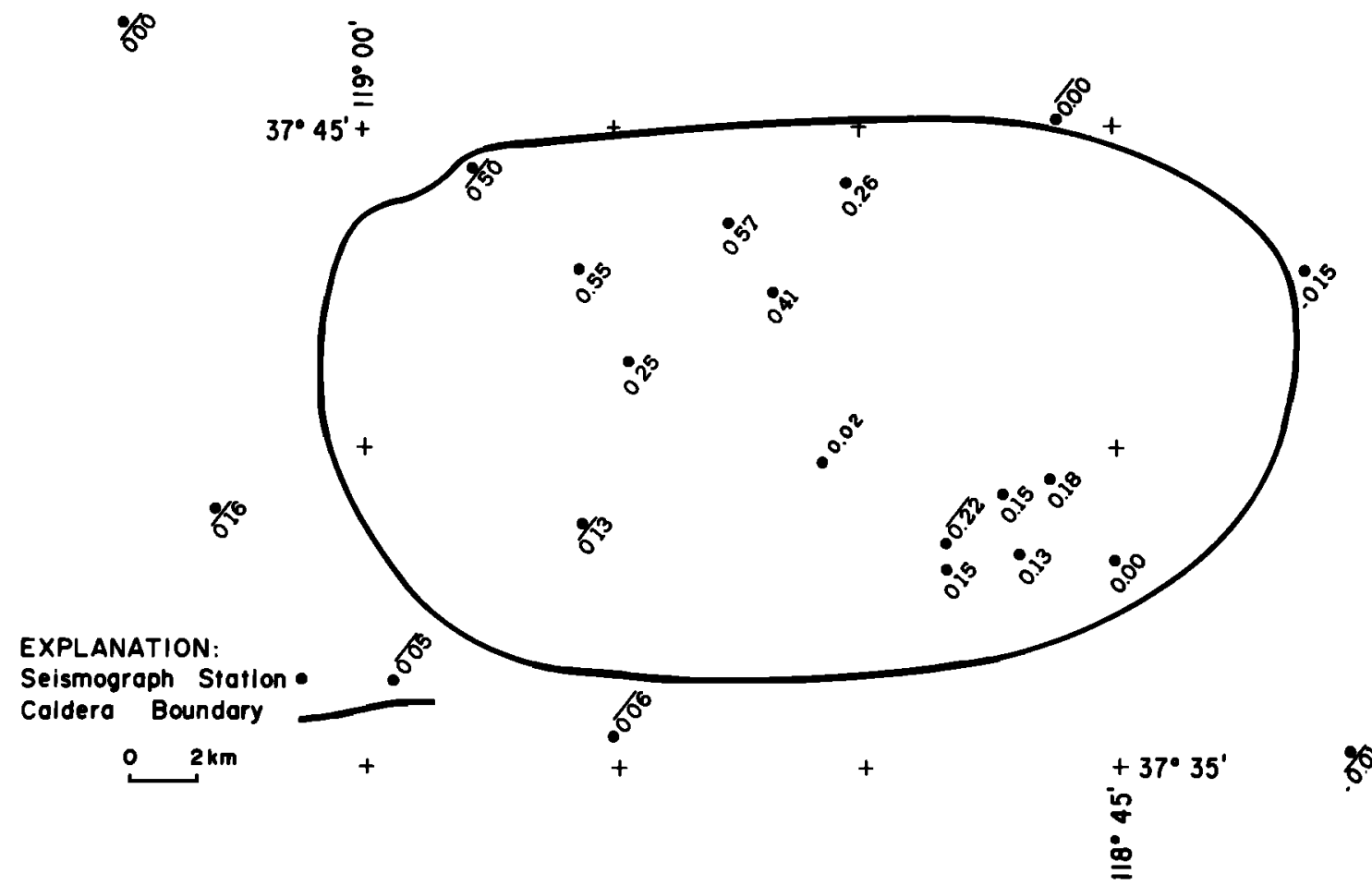

Fig. $3 b$. Teleseismic $\boldsymbol{P}$ wave residuals for events from the southeast relative to LVC (not shown). Otherwise the same as Figure $3 a$. 


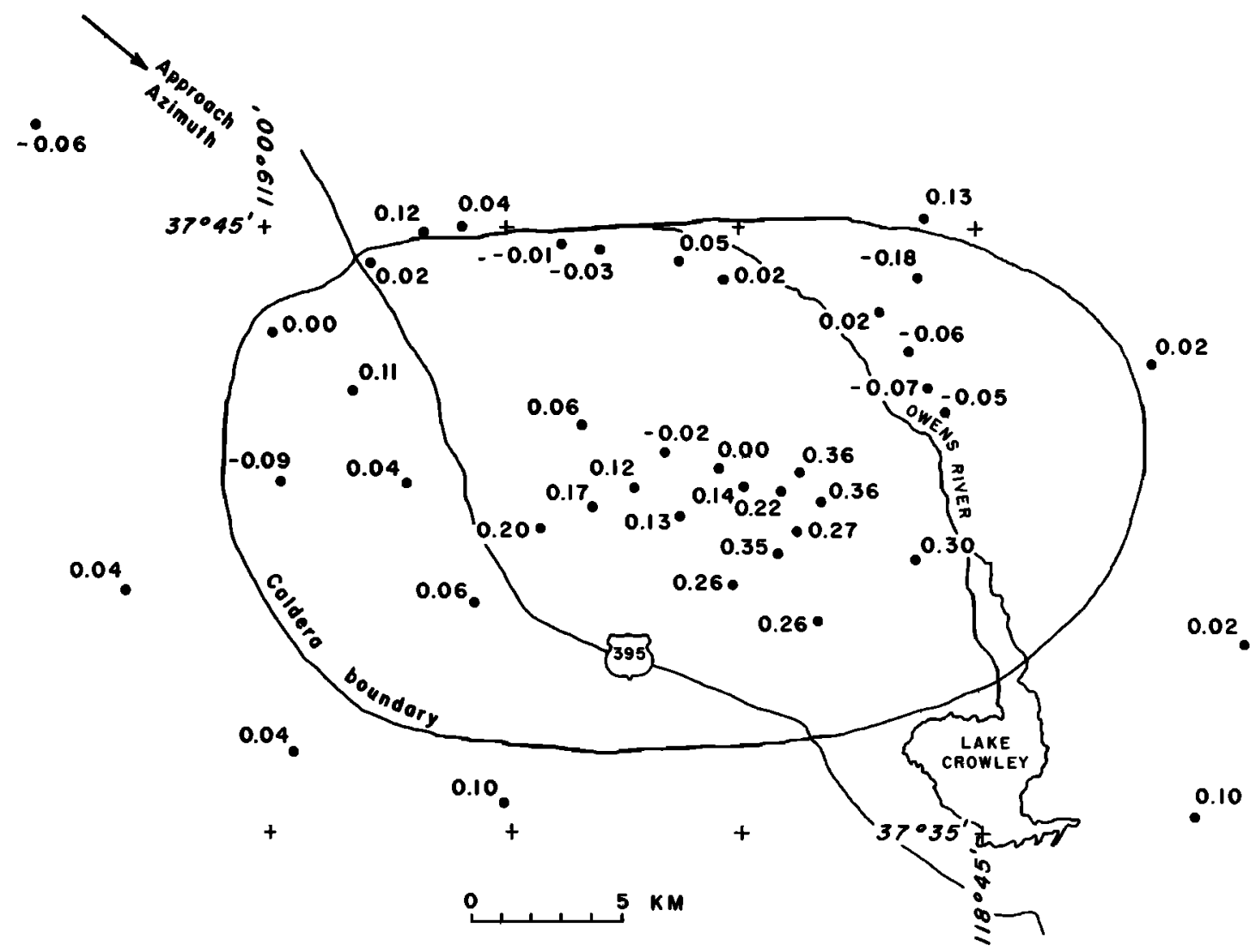

Fig. 4a. All data in Long Valley vicinity from northwest azimuth after near-surface effects have been removed as in Figure $4 c$. Station locations depicted by dots.

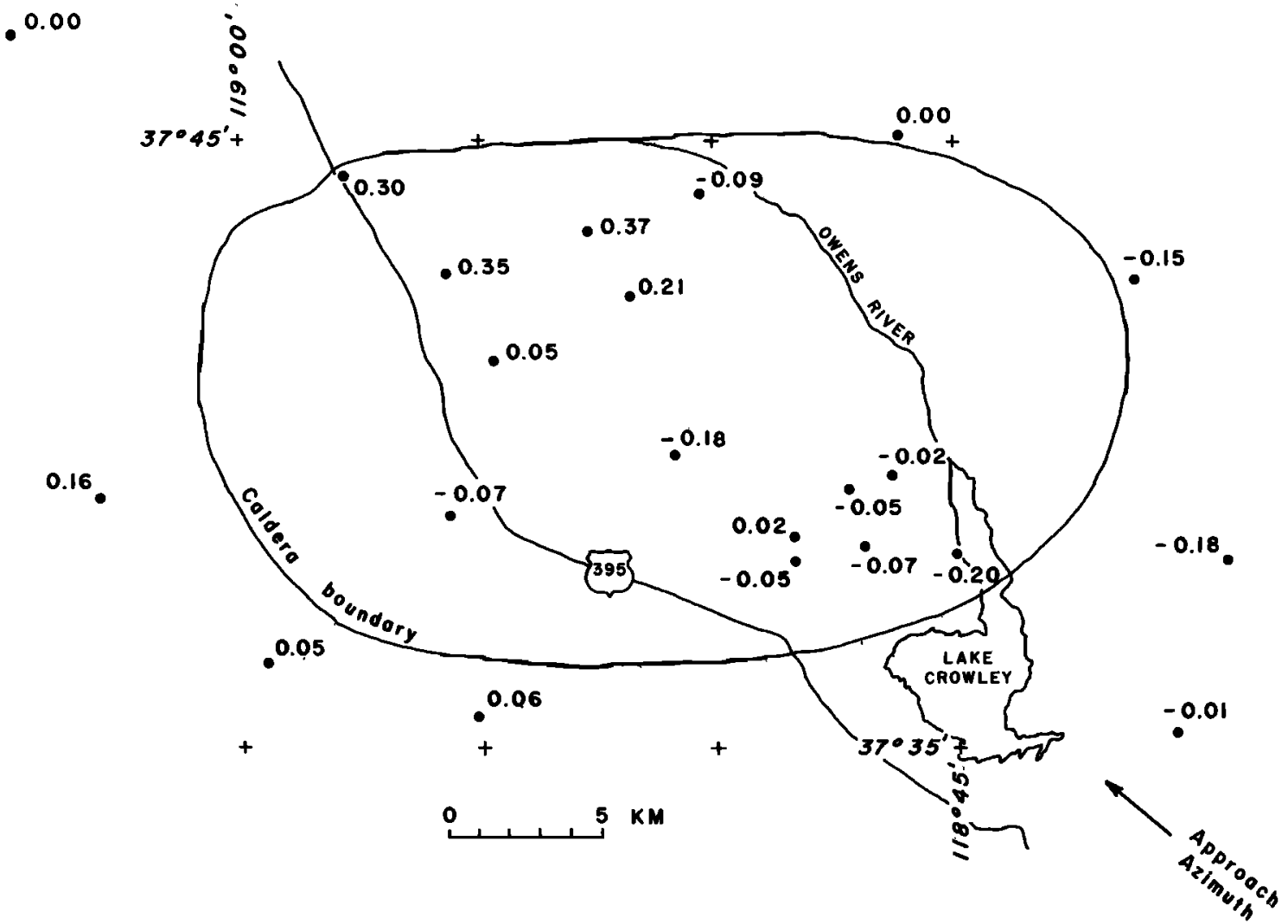

Fig. 4b. All data in Long Valley vicinity from southeast azimuth after near-surface effects have been removed as in Figure $4 c$. Station locations shown by dots. 


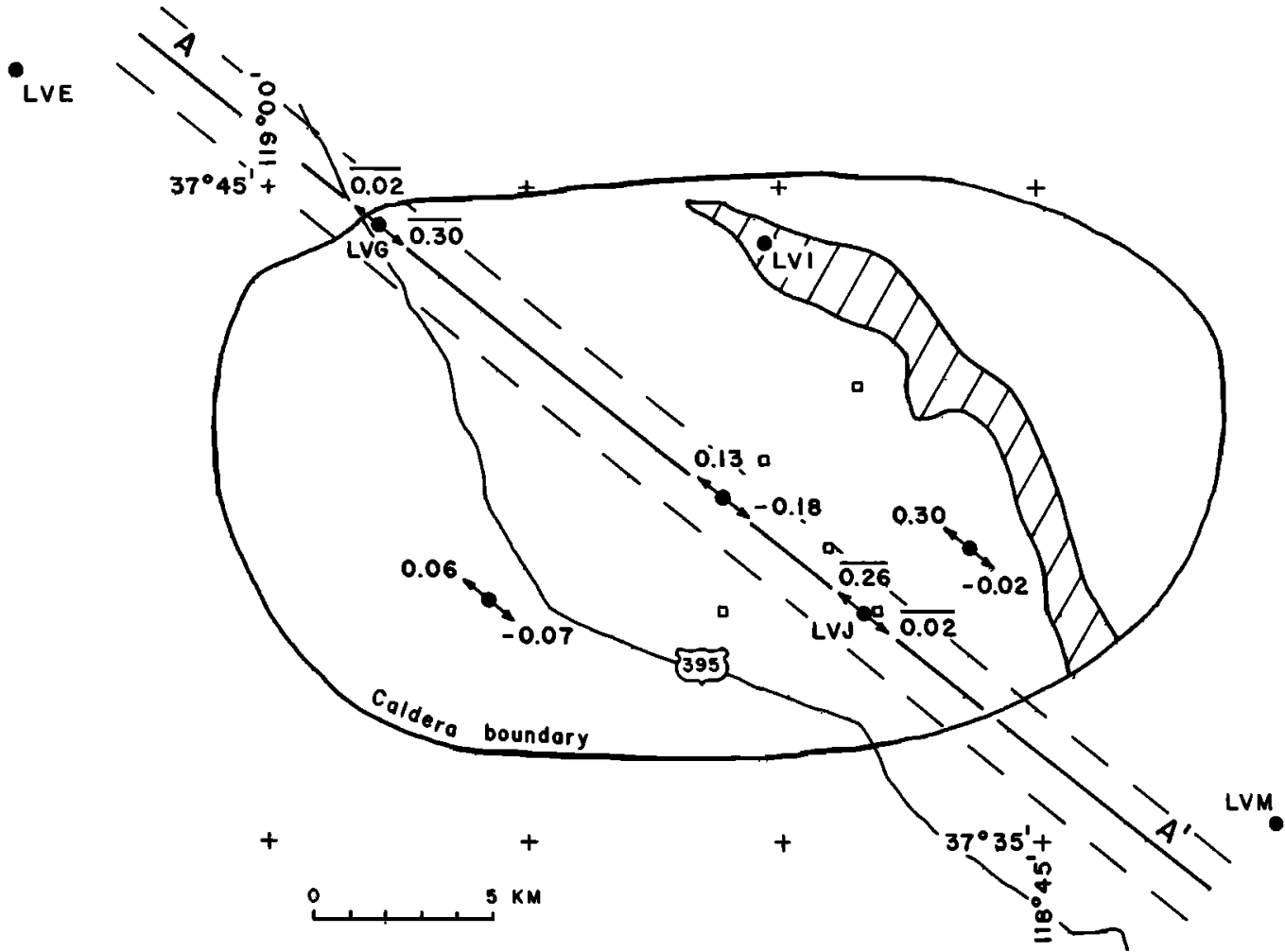

Fig. 4c. Teleseismic $P$ wave relative residuals at stations within the caldera that recorded events from both northwest and southeast with estimated near-surface effects removed. Cross-hatched area shows where near-surface effects are estimated to be $0.35 \mathrm{~s}$; elsewhere in the caldera, $0.2 \mathrm{~s}$. Note remaining corrected relative residuals of $0.3 \mathrm{~s}$ for ray paths that have penetrated up through the center of the caldera. Stations mentioned in text are identified by three-letter names. Stations within dashed lines are projected onto section AA' $^{\prime}$ in Figures $5 a$ and $5 b$. Small squares represent hot springs in the caldera.

paths outside the stippled zone in Figure $5 a$ do not detect the velocity anomaly, so the low-velocity material must be above the depth where they intersect (approximately $40 \mathrm{~km}$ ). It is impossible to fit all the required $34.2-\mathrm{km}$-long ray paths inside the stippled zone, so we conclude that the velocity decrease in the anomalous zone must be greater than $5 \%$.

A $10 \%$ velocity decrease requires anomalous ray paths only $16.2 \mathrm{~km}$ long. Figure $5 a$ shows a hypothetical model of an anomalous zone with a $10 \%$ decrease in velocity. The heavy parts of the ray paths are proportional in length to the delay seen by the ray paths. It is assumed that the material is isotropic with respect to $P$ wave velocity. The heavy parts of the intersecting ray paths must then form an internally consistent body, putting constraints on the volume that may be occupied by the anomalous zone. The models are drawn as a first approximation to fit the data and do not take into account the refraction that would occur if such an anomalous body were present. This was taken into account (and shown not to be of first-order importance) by computer ray tracing [Steeples, 1975].

Figure $5 b$ shows a $15 \%$ velocity decrease model. One event from the southeast occurred at an epicentral distance of 1450 $\mathrm{km}\left(\Delta=13^{\circ}\right)$. Events from this distance have angles of incidence determined by the upper mantle velocity and the granitic crustal velocity from Snell's law. A mantle velocity of $7.9 \mathrm{~km} / \mathrm{s}$ yields an angle of incidence of $49^{\circ}$ from vertical when a normal crustal velocity of $6.0 \mathrm{~km} / \mathrm{s}$ is assumed. If one chooses to believe data from this single event, an additional constraint is placed on the depth of the low-velocity material, since station LVE shows a delay of $0.1 \mathrm{~s}$ for the event. If that ray path to LVE and the $10 \%$ velocity decrease model were used, the delay at station LVE would be $0.3 \mathrm{~s}$ instead of $0.1 \mathrm{~s}$ for this event. On the other hand, the $15 \%$ velocity decrease model requires a delay of only $0.1 \mathrm{~s}$ at LVE and is thus preferred over the $10 \%$ velocity decrease model. This particular ray path arrived from a slightly different azimuth, however, and may not have passed through the heart of the anomalous volume.

Additional models with greater velocity contrasts could undoubtedly be constructed without developing inconsistencies in the data. At some point the wave shape of the first pulse would begin to show changes as diffraction around the lowvelocity body occurred. While we cannot now put a maximum limit on the decrease in velocity, it does not seem reasonable to expect a decrease of more than $20-30 \%$ in the $P$ wave velocity for this material, even if it is fully molten. Murase and $M c$ Birney [1973] observed velocity decreases of up to $40 \%$ in rock melts at low pressures. A similar $\mathbf{4 0 \%}$ velocity drop occurs at the core-mantle boundary, but some of that drop is due to compositional change [Bullen, 1965]. Mizutani and Kanamori [1964] observed a $P$ velocity drop of only $20 \%$ in a metal alloy upon melting. On the basis of these limited observations, $P$ velocity drops of $40 \%$ are too high for most rock melts at pressures of a few kilobars.

One may speculate upon the cause of such low-velocity material. Earthquakes of magnitude 6.0 have occurred near Long Valley caldera in the not too distant past $(1927,1941)$, so the idea of a low-velocity volume signaling an impending moderate earthquake cannot totally be ruled out. A more attractive (and more likely) hypothesis is that the low velocity is 


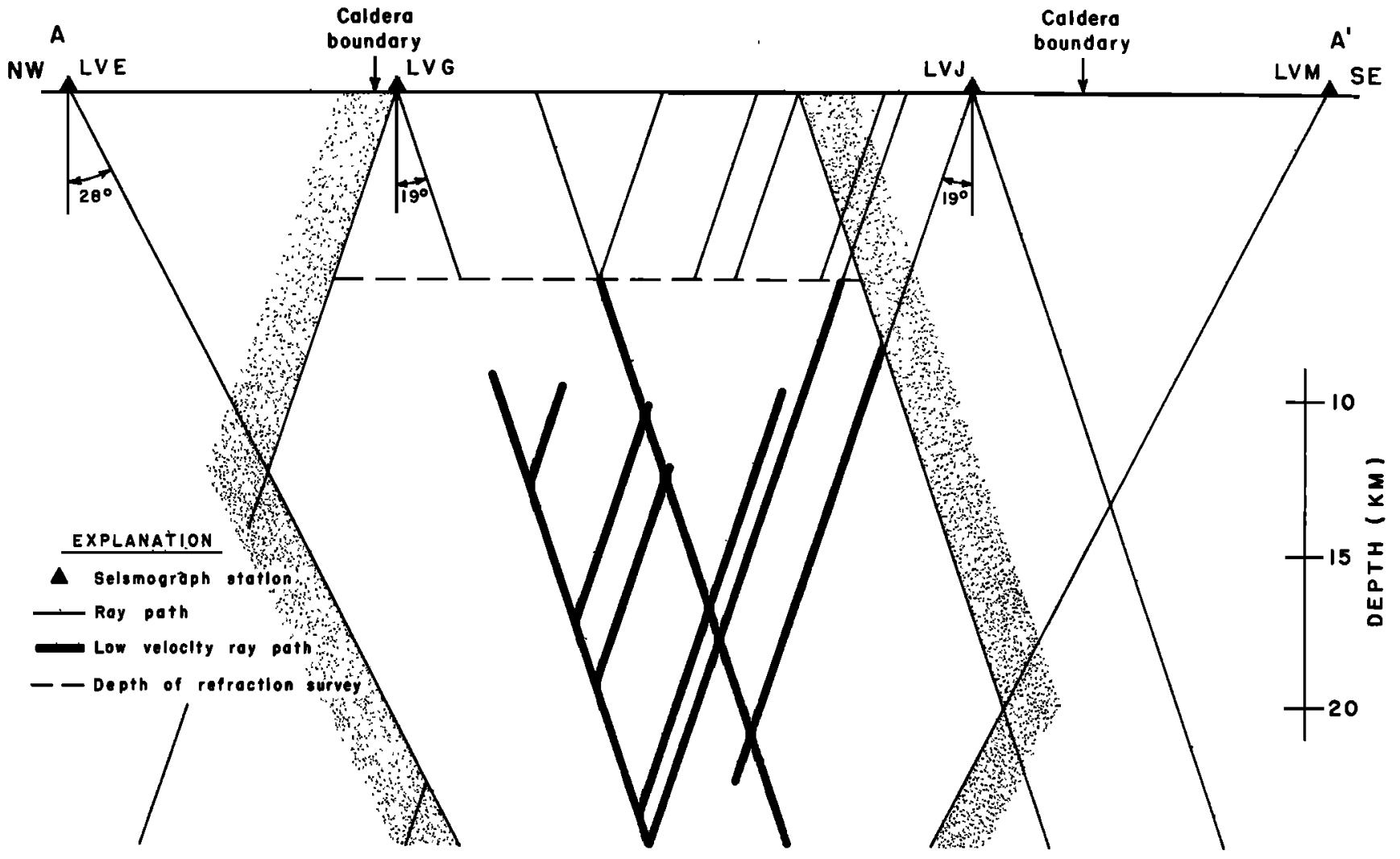

Fig. 5a. Sectional view of Long Valley caldera along $\mathrm{AA}^{\prime}$ of Figure $4 c$. Stations within $1 \mathrm{~km}$ of section line $\mathrm{AA}^{\prime}$ have been projected to the section. Model represents velocity contrast of $10 \%$ along heavy ray paths. Heavy lines on ray paths are proportional in length to delays detected along respective ray paths. Velocities outside the stippled zone are normal $(6.0 \mathrm{~km} / \mathrm{s})$, and the effects of the upper $6 \mathrm{~km}$ of material (depth penetrated by refraction survey) have been removed.

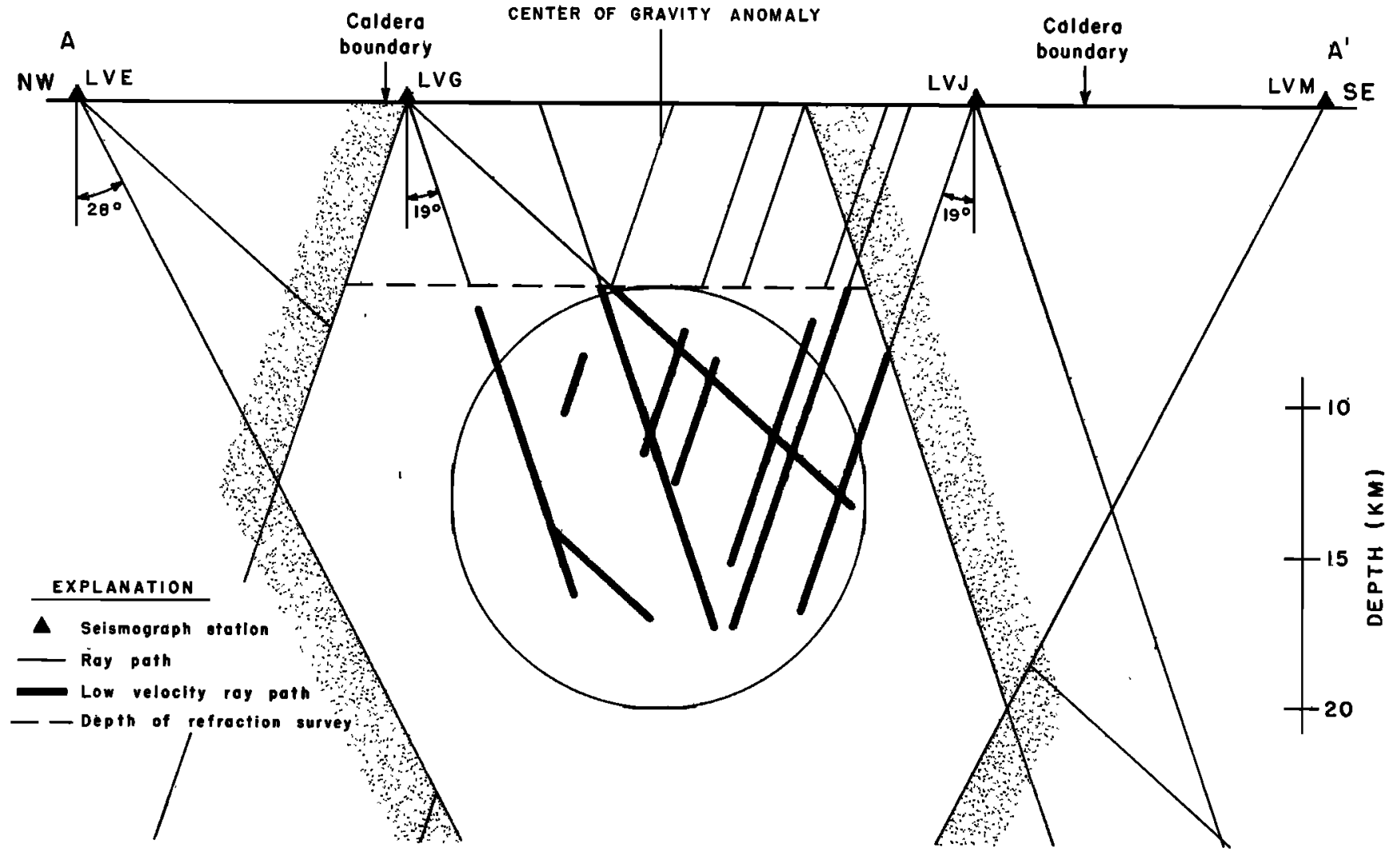

Fig. $5 b$. This model depicts a $15 \%$ velocity decrease along the heavy ray paths. The circle is a sectional view of a sphere $14 \mathrm{~km}$ in diameter. A density contrast of $0.18 \mathrm{~g} \mathrm{~cm}^{-3}$ would produce a $10-\mathrm{mGal}$ gravity anomaly at the surface directly above the center of the sphere. Otherwise the same as Figure $5 a$. 
associated with the intrusive body or bodies that fed the extrusions from the caldera vicinity in the past 700,000 years. It is interesting to note that rhyolitic extrusion has occurred in the Long Valley caldera vicinity within the past 1500 years [Bailey et al., 1976, this issue]. The resurgent part of the caldera is where the low velocity is most pronounced.

Compressional velocity in rock decreases with increase in temperature [e.g., Murase and McBirney, 1973]. If this hypothesis is true, eventually it may become possible to make a reliable heat anomaly estimate for Long Valley using the hot rock hypothesis. Such reliable estimates, however, await the collection of velocity data at $10 \mathrm{kbar}$ and $1000^{\circ} \mathrm{C}$. A $15 \%$ decrease in velocity could represent at least partial melt, but the degree of melt could be highly dependent upon the amount of water present [Spencer, 1975].

If a large volume of magma were present under the caldera, teleseismic $S$ waves would not be transmitted up through the caldera (analogous to $S$ wave attenuation at the earth's liquid core). The seismic equipment used for this experiment was not designed to record teleseismic $S$ waves, but four stations near and in the caldera (including LVG and LVJ) had 1-s horizontal seismometers. Stations both inside and outside the caldera recorded teleseismic $S$ waves, but the quality was very poor because most of the shear energy occurred at lower frequencies. It was shown, however, that the low-velocity material beneath the caldera transmits some $S$ wave energy (assuming that the angles of $P$ and $S$ incidence are equal, which may not be strictly true). This indicates that if true magma is present along the ray paths in question, it is in small pockets (probably less than $4 \mathrm{~km}$ thick, the approximate wavelength of the $S$ waves recorded), or it has sufficient viscosity to transmit $S$ waves. Local earthquake $S$ waves did not penetrate deep enough to pass through the heart of the anomalous body in the caldera [Steeples and Pitt, 1976, this issue].

The question arises whether a few thousand meters of sediment or other low-velocity material at the surface caused the observed velocity anomalies. We believe not for three reasons that have already been discussed, but we mentioned them again for emphasis because the point is critical to our study:

1. Teleseismic ray paths reaching the earth's surface are very nearly vertical, so that the amount of low-velocity material traversed near the surface is relatively independent of approach azimuth. Four stations in the caldera showed azimuthally dependent differences of $0.3 \mathrm{~s}$, which would require highly unlikely lateral heterogeneity to be explained by near-surface material.

2. The refraction survey does not show near-surface material that could cause the delays except near the Owens River valley away from most of the stations which show delays of $\frac{1}{2} \mathrm{~s}$ or more.

3. Microearthquake residuals in the caldera are out of character with the residuals normally seen in the region when Eaton's [1966] model is used. The arrivals suggest that the near-surface effects are correctly calculated by the methods in points 1 and 2 above.

Bailey et al. [1976] and Lachenbruch et al. [1976] believe that any residual magma from mid-Pleistocene intrusion must be at a depth of $10 \mathrm{~km}$ or greater in the caldera. The seismic data in this paper do not conflict with that conclusion, although Hill [1976] detected arrivals on some of his refraction records that are compatible with a low-velocity volume beginning at 7-8 km depth. Those arrivals could, however, be multiple reflections from some shallower interface. From Figures $5 a$ and $5 b$ it is evident that much of the low-velocity material probably lies in a depth range of $10-15 \mathrm{~km}$.

While the vertical and linear horizontal extent of the lowvelocity material has been somewhat constrained, nothing has yet been stated about the areal extent of the velocity anomaly. Only limited data are available to make such an approximation, but an attempt is depicted in Figure 6. In addition to data already presented, a Russian nuclear explosion and events from the southwest Pacific are plotted.

In an effort to estimate the maximum horizontal extent of the velocity anomaly, rays were projected along straight paths back toward the epicenters to a depth of $12 \mathrm{~km}$, a technique similar to that used by Iyer and Healey [1972] at Lasa. A velocity contrast of $15 \%$ is assumed so that the diameter of the dots plotted in the caldera are thickness estimates. Figure 6 shows all the rays available for projection from the teleseismic $P$ delay study at Long Valley.

A surprisingly consistent trend emerges as almost all the anomalous points plot in the west-central part of the caldera with only minor anomalous points plotted outside the caldera. The northern boundary is quite well constrained, but the eastern boundary is poorly constrained because of a lack of data points. The western and southern boundaries appear to be constrained to within about $\pm 3 \mathrm{~km}$ horizontally.

It is interesting to note that the western two thirds of the caldera appears to be more anomalous than the eastern third. Lachenbruch et al. [1976] indicated that heat flow evidence suggests that the eastern half of the caldera may have been extinct for some time. Heat flow data show a positive anomaly in the western half of the caldera. This supports our hypothesis that the western half of the caldera may have low velocity at depth due to hot rock. However, it should be remembered that heat flow data involve a time lag of the order of thousands of years for conduction from depths as shallow as $10 \mathrm{~km}$. The heat flow data therefore may not show any indication of intrusions occurring in the last thousand years or so.

A negative complete Bouguer gravity anomaly with 30$\mathrm{mGal}$ closure is centered on the Long Valley caldera [Pakiser et al., 1964]. Kane et al. [1976, this issue] have interpreted most of this gravity low in terms of up to $3 \mathrm{~km}$ of sedimentary or brecciated fill. They also pointed out the existence of gravity gradients outside the caldera that suggest a deep-seated mass deficiency beneath the caldera.

If a volume of hot rock or partial melt were present at depth in the caldera, a gravity low would result, since rock decreases in density with increase in temperature. Igneous rocks generally decrease in density from 6 to $10 \%$ upon melting [Harris et al., 1970; Murase and McBirney, 1973].

A simple theoretical deep gravity model was constructed to fit our teleseismic $\boldsymbol{P}$ delay data. The anomaly in and around the caldera can be explained in part by a buried spherical mass with its center $13 \mathrm{~km}$ deep centered on section $\mathrm{AA}^{\prime}$ as shown in Figure $5 b$. The calculation was done by using the gravitational field equation for a sphere given by Dobrin [1960, pp. 172-177] and the gravity map of Pakiser et al. [1964]. The spherical model used in the calculation had a radius of $7 \mathrm{~km}$, resulting in a required density contrast of $0.018 \mathrm{~g} \mathrm{~cm}^{-8} \mathrm{mG}^{-1}$. If one chooses to attribute a $10-\mathrm{mGal}$ anomaly to this hypothetical sphere, a density contrast of $0.18 \mathrm{~g} \mathrm{~cm}^{-9}$ is required. The observed gravity gradients outside the caldera do not allow a spherical mass much larger, deeper, or less dense than the model just discussed. Density of rock decreases with increase in temperature because of thermal expansion, so up to 10 


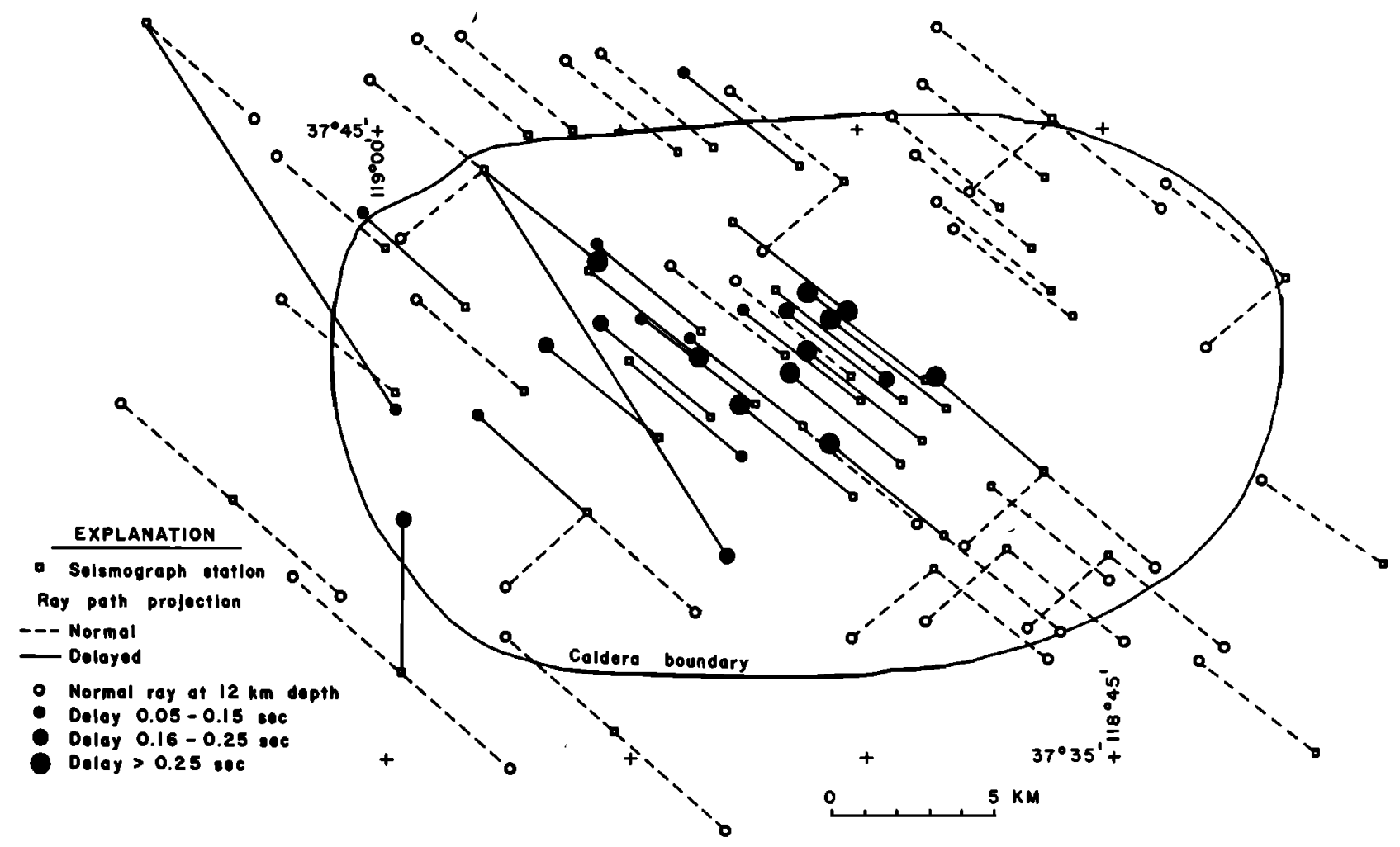

Fig. 6. Rays are projected back toward the epicenters to a depth of $12 \mathrm{~km}$, nonrefractive paths being assumed. Note that almost all anomalous points form an internally consistent body in the west-central part of the caldera.

$\mathrm{mGal}$ in excess of the observed $30 \mathrm{mGal}$ gravity anomaly in the caldera could be due to hot rock and/or partial melt. It should be pointed out that rock density decreases only about $1 \%$ for each $400^{\circ} \mathrm{C}$ change in temperature [Skinner, 1966]. That in turn implies that the density change of hot rock without partial melt could produce no more than about $3 \mathrm{mGal}$ of gravity anomaly for the model just discussed. This indicates that if the deep gravity model is accurate and compositional change is not a factor, then some degree of partial melt is needed to explain the rest of the gravity anomaly.

\section{CONCLUSIONS}

The low $P$ velocity observed beneath Long Valley is probably caused by anomalously high temperature. The anomalous zone is more than $7 \mathrm{~km}$ but definitely less than $\mathbf{4 0}$ $\mathrm{km}$ deep, probably less than $25 \mathrm{~km}$ deep. The velocity contrast with the surrounding material is more than $5 \%$ and is probably in the range $10-15 \%$. The areal extent of the low-velocity material is poorly constrained but is probably confined to the caldera, possibly to the west half of the caldera. A possible deep-seated gravity low lends circumstantial support to our hot rock/partial melt hypothesis.

The teleseismic $P$ delay technique may become a viable method of exploring the sources of geothermal energy. It should not be used without a thorough knowledge of the upper crustal velocity structure such as that normally obtained from seismic reflection or refraction surveys. In addition to vertical instruments, it is desirable to use horizontal seismometers capable of recording teleseismic $S$ waves so that $S$ delays and possible $S$ attenuation can be investigated in conjunction with $P$ wave studies.

Timing the first or second zero crossing may be one way of attaining better relative accuracy in measuring arrival times, particularly for marginal quality events. The technique is probably most useful on small aperture arrays. One can determine the applicability of the zero crossing timing method by timing both first arrival and zero crossings for high quality events and comparing the two methods. In our case, the two timing methods produce the same results, but the zero crossing method allows the use of about 50\% more data while it decreases the scatter in the data.

The estimation of heat anomalies by the teleseismic $P$ delay method awaits the laboratory measurement of rock velocities at pressures approaching $10 \mathrm{kbar}$ and temperatures of $1000^{\circ} \mathrm{C}$.

Acknowledgments. The field data for this study were obtained by John Coakley, and records were prepared by Jeanne Taylor. Extensive and fruitful discussions with Dave Boore, Dave Hill, and George Thompson were appreciated. The manuscript was critically reviewed by Dave Boore, Dave Hill, and Bob Engdahl. Publication authorized by the Director of the U.S. Geological Survey.

\section{REFERENCES}

Bailey, R. A., G. B. Dalrymple, and M. A. Lanphere, Volcanism, structure, and geochronology of Long Valley caldera, Mono County, California, J. Geophys. Res., 81. this issue, 1976.

Bolt, B. A., and $\mathbf{O}$. W. Nuttli, $P$ wave residuals as a function of azimuth, 1, Observations, J. Geophys. Res., 71, 5977-5986, 1966.

Bullen, K. E., An Intraduction to the Theory of Seismology, 3rd ed., pp. 217-249. Cambridge University Press, London, 1965.

Chinnery, M. A., and $M . N$. Toksoz, $P$-wave velocities in the mantle, 1, Below 700 km, Bull. Seismol. Soc. Amer., 57, 199-226, 1967.

Cramer, C. H., and R. L. Kovach, A search for teleseismic travel-time anomalies along the San Andreas Fault zone, Geophys. Res. Lett., 1, 90, 1974.

Dobrin, M. B., Introduction to Geophysical Prospecting, 2nd ed., pp. 172-177, McGraw-Hill, New York, 1960. 
Eaton, J. P., Crustal structure in northern and central California from seismic evidence, Calif. Div. Mines Geol. Bull., 190, 419-426, 1966.

Eaton, J. P., M. E. O'Neill, and J. N. Murdock, Aftershocks of the 1966 Parkfield-Cholame, California earthquake: A detailed study, Bull. Seismol. Soc. Amer., 60, 1151-1198, 1970.

Harris, P. G., W. Q. Kennedy, and C. M. Scarfe, Volcanism versus plutonism-The effect of chemical composition, in Mechanism of Intrusion, edited by Geoffrey Newall and Nicholas Rast, Geol. J. Spec. Issue 2, 187-200, 1970.

Herrin, E., Introduction to '1968 seismological tables for P phases,' Bull. Seismol. Soc. Amer., 58, 1193, 1968.

Hill, D. P., Structure of Long Valley caldera from a seismic refraction experiment, $J$. Geophys. Res., 81, this issue, 1976.

Iyer, H. M., Anomalous delays of teleseismic $P$-waves in Yellowstone National Park, Nature, 253, 425-427, 1975.

Iyer, H. M., and J. H. Healy, Teleseismic residuals at the Lasa-USGS extended array and their interpretation in terms of crust and upper mantle structure, J. Geophys. Res., 77, 1503, 1972.

Iyer, H. M., and T. Hitchcock, Seismic noise survey in Long Valley, California, J. Geophys. Res., 81, this issue, 1976.

Iyer, H. M., J. R. Evans, and J. Coakley, Teleseismic evidence for the existence of low-velocity material deep into the upper mantle under the Yellowstone caldera (abstract), Eos Trans. AGU, 55, 1191, 1974.

Kane, M. F., D. R. Mabey, and R. Brace, A gravity and magnetic investigation of the Long Valley caldera. Mono County, California, $J$. Geophys. Res., 81, this issue, 1976.

Koizumi, C. J., A. Ryall, and K. F. Priestley, Evidence for a highvelocity lithospheric plate under northern Nevada, Bull. Seismol. Soc. Amer., 63, 2135-2144, 1973.

Lachenbruch, A. H., M. L. Sorey, R. E. Lewis, and J. H. Sass, The near-surface hydrothermal regime of Long Valley caldera, $J$. Geophys. Res., 81, this issue, 1976.

Mack, H., Nature of short-period $P$ wave signal variations at Lasa, $J$. Geophys. Res., 74, 3161-3170, 1969.

Mizutani, H., and H. Kanamori, Variation of elastic wave velocity and attenuative property near the melting temperature, $J$. Phys. Earth, 12(2), 43-49, 1964.

Murase, T., and A. R. McBirney, Properties of some common igneous rocks and their melts at high temperatures, Geol. Soc. Amer. Bull., 84, 3563-3592, 1973.

Niazi, M., and D. L. Anderson, Upper mantle structure of western North America from apparent velocities of $P$ waves, $J$. Geophys. Res., 72, 4633, 1965.

Nuttli, O. W., and B. A. Bolt, $P$ wave residuals as a function of azimuth, 2, Undulations of the mantle low-velocity layer as an explanation, J. Geophys. Res., 74, 6594-6602, 1969.

Pakiser, L. C., M. F. Kane, and W. H. Jackson, Structural geology and volcanism of Owens Valley region, California-A geophysical study, U.S. Geol. Surv. Prof. Paper 438, 68 pp., 1964.

Pitt, A. M., and D. W. Steeples, Microearthquakes in the Mono Lake-Northern Owens Valley region from September 28 to October 18, 1970, Bull. Seismol. Soc. Amer., 65, 835-844, 1975.

Press, F., and S. Biehler, Inferences on crustal velocities and densities from $P$ wave delays and gravity anomalies, $J$. Geophys. Res., 69. 2979, 1964.

Richter, C. F., Elementary Seismology, pp. 664-666, W. H. Freeman, San Francisco, 1958.

Skinner, B. J., Thermal expansion, in Handbook of Physical Constants, rev. ed., edited by S. P. Clark, Jr., Geol. Soc. Amer. Mem. 97, 75-96, 1966.

Spencer, J. W., Jr., Ultrasonic velocities in rocks under crustal conditions, Ph.D. thesis, Stanford University, Stanford, Calif., 1975.

Steeples, D. W., Teleseismic $P$-delays in geothermal exploration with application to Long Valley, California, Ph.D. thesis, Stanford University, Stanford, Calif,, 1975.

Steeples, D. W., and A. M. Pitt, Microearthquakes in and near Long Valley, California, J. Geophys. Res., 81, this issue, 1976.

Utsu, T., Temporal variations in traveltime residuals of $P$-waves from Nevada sources, J. Phys. Earth, 21, 475-480, 1973.

Wyss, M., and D. J. Holcomb, Earthquake prediction based on station residuals, Nature. 249, 139, 1973.

(Received December 26, 1974; revised July 31, 1975; accepted July 31, 1975.) 